\title{
PRODUCT CIRCULARITY INDICATORS: WHAT CONTRIBUTIONS IN DESIGNING FOR A CIRCULAR ECONOMY?
}

\author{
M. Saidani ${ }^{1,2, 凶}$, H. Kim ${ }^{1}$, F. Cluzel ${ }^{2}$, Y. Leroy ${ }^{2}$ and B. Yannou ${ }^{2}$ \\ ${ }^{1}$ University of Illinois at Urbana-Champaign, United States of America, ${ }^{2}$ CentraleSupélec, France \\ $\triangle$ michael.saidani@centralesupelec.fr
}

\begin{abstract}
This paper investigates and questions the relevance of product-centric circularity indicators in a product design context. To do so, reviews of eco-design tools and critical analyses of circularity indicators at the micro level of circular economy implementation are combined with a new workshop experimenting four of these indicators with the aim to improve the circularity performance of an industrial product. On this basis, the four tool-based circularity indicators tested are mapped on the engineering design and development process, and are positioned among the pool of main eco-design tools.
\end{abstract}

Keywords: circular economy, circularity indicators, design process, design for $x(D f X)$, case study

\section{Introduction}

\subsection{Motivation and objectives}

Circular economy (CE) practices can contribute significantly in a sustainable industrial development through the superior design of products and systems, keeping the added value of manufactured products in the economy, and minimizing the generation of waste. Closing the loop on materials and products can notably be achieved by long-lasting design, maintenance, repair, reuse, remanufacturing, refurbishing, and recycling (Geissdoerfer et al., 2017; Franco, 2019). Product design is particularly the starting point for any circular product or system, and it has been acknowledged that up to $80 \%$ of products' sustainability performance can be influenced during the design phase (McAloone and Bey, 2009). Indeed, design science can support the transition towards more circular practices, notably through the means of "product, services and systems design", "design methods and tools", and "design for X", and by integrating circular design strategies and guidelines in the early phases of the design process (Pigosso and McAloone, 2017). In the meantime, the development of a sustainable $\mathrm{CE}$ first requires to measure and monitor the circularity performance of systems and, accordingly, numerous circularity indicators (c-indicators) have been proposed at different levels of the CE implementation in the last few years (Parchomenko et al., 2019; Saidani et al., 2019a). C-indicators are defined here as measuring instruments to quantify the performance and progress of systems in a circular economy perspective. The present paper focuses on the circularity performance of industrial products, and the c-indicators considered in this study are the ones classified under the cluster product-centric c-indicators. Note that while the emphasis is put on cindicators at micro level implementation of CE, elements like circular business models or reverse cycles performance are still captured to a certain extent by the product $\mathrm{c}$-indicators. 
This piece of research aims to investigate how these c-indicators and their assessment framework (including computer-based tools) can help designing within the circular economy paradigm. In other words, it aims to provide new insights on how product-level c-indicators can support industrial practitioners in designing circular and sustainable technical products?

On the one hand, it has been stated that c-indicators are necessary to ensure and manage a sustainable transition to more $\mathrm{CE}$ practices, as c-indicators are a way to assess change (compared to the linear "take-make-waste" economy), have the ability to summarize great complexity, contribute to the need of shortcuts and rules of thumb to support decision-making, and can be used for various purposes (e.g., information, decision-making, communication, and/or learning purposes) as reviewed and summarized in Saidani et al. (2019a). Yet, their positioning and suitable application during the product design and development process still need to be further addressed, in order to foster their appropriate uptake in the new development or re-design of products.

On the other hand, the list of design features or attributes that can enable or contribute to product circularity is extensive (Bovea and Pérez-Belis, 2018), and numerous eco-design tools and approaches already exist to support designers to take informed decisions regarding e.g., material selection or product architecture. Yet, the actual adoption of these tools within industrial practices is still marginal. On this basis, it seems relevant to build on the momentum that the CE concept has among businesses and politics to figure out: (i) how these recently developed c-indicators and associated tools can be complementary to existing eco-design tools, and (ii) what is their positioning within the extensive pool of methods and tools aiming to mitigate the environmental footprint of products. In this line, the overall research question of this study is: how recently developed product-centric c-indicators and their assessment framework can support circular design? This guiding question is divided into three sub-questions that are addressed in this paper, namely:

- What is the positioning and relation(s) between eco-design tools and product-level cindicators?

- How do these c-indicators fit into the design process, and what contribution(s) do they bring?

- To what extent can they be used as a tool to enable the design of CE-friendly products?

The expected outputs and contributions of this piece of research, as summarized in Figure 1, are therefore to provide new empirical insights on how c-indicators can provide relevant circular design guidelines, and practical guidance to generate eco-improvement on existing products (sub-section 4.1). Also, discussions are made on their role and place within the wide pool of eco-design and eco-innovation tools (sub-section 4.2). Recommendation are thus given to select and apply the right c-indicators according to the specific stages of the design and development process of products. Eventually, shortcomings of current c-indicators are pointed out and promising areas for future research are depicted.

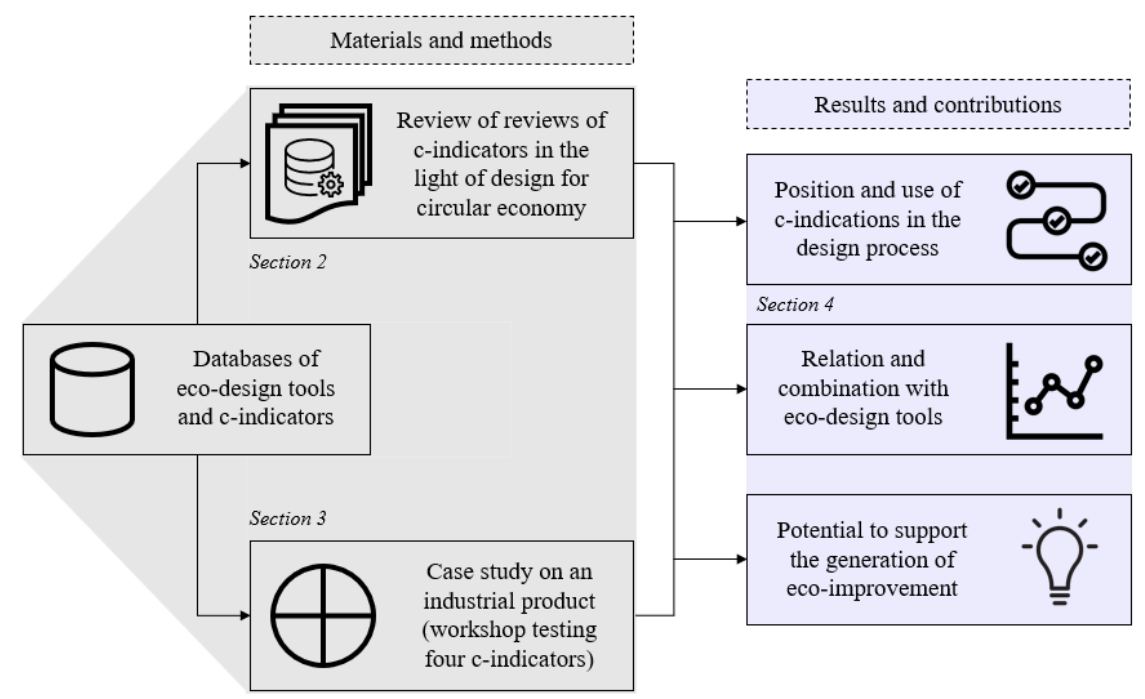

Figure 1. Synopsis of the paper and overall research approach 


\subsection{Research approach}

To answer these questions, the present work combines, as illustrated in Figure 1: (i) a review of the latest publications focusing on c-indicators at the micro level of CE implementation; (ii) an analysis of these c-indicators in the light of their application during the design and development process of products; and (iii) a workshop experimenting several c-indicators on an industrial product, with the aim to augment its circularity performance through design improvements. Compared to previous research, we dive here more thoroughly into the potential use of c-indicators in the engineering design and development process as a tool and enabler to design for circularity. We question in which ways these c-indicators can be integrated or deployed as replacement, complementary, and/or supplementary solutions to eco-design and eco-innovation tools. As such, the literature summary on cindicators is performed through the lens of their potential use during the design process to improve the circularity performance of products. Complementary to previous workshops experimenting cindicators, e.g., the ones conducted in 2017 and 2018 (Saidani et al., 2019b) to test their robustness, user-friendliness or compliance with CE principles, the newly developed workshop aims to test four product-centric c-indicators in order to evaluate empirically how they can contribute in the generation of eco-improvement on an industrial product. This workshop and related case study on a real-world product give concrete examples on how c-indicators can advance the design and development of products in a circular economy perspective.

\section{Literature review}

The literature review section is divided into three parts. First, to position adequately product-level cindicators in the process of designing and developing new products, the different steps of the engineering design process are outlined. Second, the positioning of eco-design and eco-innovation tools in the design process is analyzed, in order to enable the comparison with c-indicators and their associated assessment framework,. Third, the latest publications addressing the critical analysis of product-level c-indicators are reviewed in the light of designing for a circular economy.

\subsection{Engineering design process}

The structure or breakdown of the product design and development process in different steps or phases has been long studied. Several models have been proposed by researchers. These models vary from their levels of detail, number of steps, degrees of complexity, and technical terminologies. For instance, the systematic approach of engineering design described by Pahl and Beitz (2007) is a sequence of four phases: (i) task clarification, that deals with collecting, formulating and documenting the needs and requirements of the product to be designed; (ii) conceptual design, that addresses the identification of the basic principles and the draft of a design concept or solution; (iii) embodiment design, that elaborates the design into a layout that satisfies various technical and economic criteria; and (iv) detail design, that finalizes the design and prepares production documents. On the other hand, Rodrigues et al. (2016) classified key performance indicators for product development according to the following phases of the product design and development process: (i) product strategic planning, (ii) informational design, conceptual design, (iii) detailed design, (iv) product preparation, (v) product launch, (vi) product accompaniment and monitoring. In a complementary manner, the content of TheDesignExchange (2017), an online database of design methods and tools, is categorized according to the five phases of the early stage design process, namely design tools to: (i) research, i.e. to collect data to better understand customer needs and context; (ii) analyze, i.e. to study and/or synthesize collected data; (iii) ideate, i.e. to generate new concepts and solutions for products, services; (iv) prototype, i.e. to turn ideas into reality through a variety of mediums; and (v) communicate, i.e. to exchange at all stages of the design process with actors outside of the design team.

In addition, two core activities are of the utmost importance during the conceptual and detailed design phases to design and develop with eco-friendly products (Vallet et al., 2016): first, the environmental assessment phase (aiming at evaluating the environmental impacts of an existing product), and second, the environmental improvement phase (focusing on the generation of environmentally friendly solutions). Tyl et al. (2014) proposed a workshop process in four phases to facilitate the eco-ideation 
and eco-selection of design concepts or solutions, namely: awareness, preparation, ideas generation, and ideas selection. Recently, Sustainn (2018) looked at integrating the circular economy mindset into the conceptual design phase, using several circular design frameworks, such as design for durability, disassembly, repair, upgrade, remanufacturing, and/or recycling. In parallel, before proceeding to the detailed design phase, assessing the competitiveness (e.g., in terms of quality, cost, delivery) and the circularity performance of the conceptual and potential solutions is the key to a successful design and development process. In this line, it would be relevant to further explore, here through a workshop and its related industrial case study, how product-level c-indicators can both help to generate circular design ideas and to evaluate promising circular concepts.

\subsection{Eco-design and eco-innovation tools}

The importance of integrating eco-design practices and tools in the early phases of new product development to foster to the design of sustainable products has been highlighted by numerous scholars (Jugend et al., 2020). The methods and tools supporting eco-design and eco-innovation have also been extensively reviewed and categorized by researchers, notably according to their applicability to particular phases of the design process or product life cycle, to their scope or level of system thinking involved, and to the type of guidance offered. For instance, Ramani et al. (2010) mapped on a twodimensional chart the most acknowledged eco-design tools developed between 1995 and 2010, following their appropriate positioning in the design phase, between conceptual design and detailed design (y-axis), and whether they require qualitative knowledge or quantitative data (x-axis). Bovea and Pérez-Belis (2012) developed a classification of eco-design tools considering the degree of difficulty and time needed to implement them, in addition to their suitability for environmental assessment, generation of design alternatives, and selection of opportunities for improvement. The five phases of the design process adopted in the taxonomy developed by Bovea and Pérez-Belis (2012) are the following: (i) functional description, (ii) requirements definition, (iii) design alternatives generation, (iv) design alternatives comparison, and (v) selection.

By focusing on the ways eco-design and eco-innovation tools can promote a circular economy, Smol et al. (2017) emphasized the need for more empirical methods to assess and qualify the mutual influence and role of such tools in implementing a circular economy. According to de Jesus et al. (2018), eco-innovation is an essential element in catalyzing the transition from a linear to a circular system of production and consumption, and several authors stated as well the benefits and compatibility of incorporating the contribution from eco-innovative solutions into CE strategies, and vice versa (Gente and Pattanaro, 2019). Yet, Hollander et al. (2017) argued that eco-design (with tools rooted in the linear economy) and circular product design differ on a fundamental level, and that circular product design requires a new, or at least an adapted, set of methods and tools. According to the typology depicted by Hollander et al. (2017), circular product design should incorporate both design for product integrity (aiming at preventing and reversing obsolescence at a product and component level) and design for recycling (aiming at preventing and reversing obsolescence at a material level). Eventually, they encourage design researchers to further question the validity of these guiding principles, methods and tools when attempting to design for CE. With this background, it becomes interesting to position and compare the recently developed c-indicators (and their associated computational tools) against eco-design and eco-innovation tools.

\subsection{Circularity indicators and associated measurement framework}

As the number of publications related to CE increases exponentially (Blomsma et al., 2019), the variety of measuring instruments to assess the performance of products, services and systems in a $\mathrm{CE}$ perspective is growing accordingly. In parallel, c-indicators are being analyzed and experienced by researchers from several standpoints, e.g.: a database of 55 c-indicators classified into a 10-dimension taxonomy and an associated computer-based tool to select suitable c-indicators (Saidani et al., 2019a); 63 CE metrics, scrutinized thought multiple correspondence analysis, and grouped into 3 clusters including a product-centric one (Parchomenko et al., 2019); 270 leading sustainability-related performance indicators, to assess the sustainability of $\mathrm{CE}$ initiatives, classified and available via an Excel spreadsheet 
(Kravchenko et al., 2019). Yet, the actual integration and use of such indicators during the design and development phases of products still need to be further investigated and discussed.

Through the development and experimentation of their product-level c-indicator, the circular economy indicator prototype (CEIP), Cayzer et al. (2017) questioned if it leads to relevant decision-making support. They found out that the CEIP may improve decision-making in the identification and selection of CE strategies thanks to a widespread diffusion of circular thinking, but it should not be the sole source of decision-making, and they mentioned the circularity potential score should be taken as indicative rather than definitive. In a complementary manner, the soundness and robustness of four c-indicators at a micro level of CE implementation (the CEIP, the circular economy toolkit (CET), the circularity potential indicator (CPI), and the material circularity indicator (MCI)) have been discussed based on two complementary workshops, making several groups experiencing these c-indicators on the same industrial product (Saidani et al., 2019b). Ruiz-Pastor et al. (2019) examined as well to what extent four cindicators (the CET, the Circular Spider Map, the MCI, and the product circularity metric (PCM)) can be applied to measure the circularity potential of concepts during the early design stage. By comparing the information required to use them at a product level, they conclude the PCM and the MCI are not intended for the conceptual phase of design, as the necessary data to compute them are very concrete, which is not usually possible when dealing with conceptual designs. While the two other c-indicators can provide directions to generate CE-oriented conceptual design, the authors noticed some shortcomings when it comes to assess quantitatively the circularity performance. Last but not least, Janik and Ryszko (2019) performed a thorough examination and comparison of the $19 \mathrm{c}$-indicators at the micro level of CE implementation inventoried in the taxonomy of CE indicators (Saidani et al., 2019a). The in-depth analysis of these c-indicators aimed to determine their usefulness for practical application in companies, as well as their potential to support the decision-making process from a managerial perspective. They assessed each of the $19 \mathrm{c}$-indicators according to the following criteria: time consumption to deploy the c-indicator; scope and detail of the required data; specialized knowledge and competence to apply the cindicator. The results of this comparative study indicate that the most suitable indicators to support decision-makers in the assessment of $\mathrm{CE}$ initiatives, strategies or concepts at a product level are the circularity calculator (CC), CEIP, CET, CPI and resource duration indicator (RDI).

\section{Workshop: experimentation of c-indicators to re-design a product}

\subsection{Presentation of the industrial case study and purpose of the workshop}

To provide new and complementary insights on the positioning and appropriate use of c-indicators during the design and development process, a workshop experimenting four product-level c-indicators (each one being embedded in a computer-based tool) is conducted. The objective of this workshop is to improve the circularity performance of an industrial product based on the outcomes of these c-indicators. An industrial case study on a real-world technical product (a catalytic converter for heavy vehicles that contains a non-negligible amount of platinum) is used as a support for this workshop. The purpose of this experimentation is to evaluate empirically how and to what extent the outputs delivered by productlevel c-indicators can be leveraged to generate relevant eco-improvements and/or eco-innovations to enhance the circularity performance of a product. The results of this newly developed workshop are compared with a previous workshop (Saidani et al., 2016) conducted on the same product but using the eco-design strategy LiDS wheel, as a tool to generate eco-innovations. The following industrial context and requirements were provided to the participants before the selection and experimentation of the cindicators: "A project manager has recently heard about the circular economy concept. As such, he wants to know how the catalytic converters they design and develop could be more circular to retain the value of precious metals in their business operations. The project manager is interested in the impacts of future designs and potential business models changes on the performance of the intrinsic circularity of his product. $\mathrm{He}$ is particularly looking for indicators aiming at evaluating the circularity potential improvement during design and development process, and wants to consider all possible loops of the circular economy." A simplified two-page and non-confidential model of the catalytic converter was provided, including information related to: the pre-life of the product (bill of materials, production process, recycled feedstock), the life of the product (usage, lifespan, emissions), the end-of-life of the 
product, and complementary information related to the value chain, including geographical and logistic information. With this essential information, the participants were able to rapidly get familiar with the product and its eco-systems, and thus to compute properly the c-indicators. For information, the materials and resources to reproduce a similar hands-on workshop on c-indicators are available on demand, or in the Appendix of Saidani's PhD thesis (2018), including notably: the life cycle inventory for the industrial case study, and the responses documents with guidelines to compute the c-indicators.

\subsection{Organization of the workshop and c-indicators tested}

This workshop was conducted during the doctoral school "EcoDoCS'2019" (Eco-design of Complex Systems), funded by the EcoSD and S-mart networks, and endorsed by the Design Society. It followed the same half-a-day format than the two workshops already conducted in 2017 and 2018 to assess the scientific soundness and robustness of four c-indicators reported in Saidani et al. (2019b). Yet, in this 2019 workshop session, after the selection and computation of suitable c-indicators, instead of performing a critical analysis of the c-indicators tested, participants were asked to propose ecoimprovements on the product based on the outputs of these c-indicators. For this session, participants were $\mathrm{PhD}$ students in the fields of eco-design, industrial ecology, or circular economy. During the first part of the workshop, several c-indicators at a micro level of the CE implementation were presented, and the industrial case study was introduced (see Figure 2). Next, participants - divided into four groups of three persons - used the C-Indicators Advisor, now available online as shown in Figure 3, to identify and select suitable c-indicators that would fit with the requirements of the case study. Then, each group experienced two c-indicators among the four selected both to assess the circularity performance of the product and to propose ideas, concepts and/or solutions to improve its circularity potential. The four cindicators selected are the MCI, CPI, CET and CEIP, as detailed through Figure 3. These c-indicators have been selected because they: fit with the industrial requirements of the case study, are focused on material- and product-level circularity, assess the intrinsic circularity performance, consider both actual and potential circularity performance, and are linked to accessible computer-based tools. Additional description of these four c-indicators are available in Saidani et al. (2019b). Note that the workshop was developed in accordance with the guidelines of the Design Research Methodology (Blessing and Chakrabarti, 2009), i.e., each of the four groups has experienced two c-indicators in order to be able to compare them, and one control group has been used as a comparative baseline. Finally, the propositions made by one group to improve the circularity performance of the product were assessed by another group according to four criteria (namely, economic feasibility, technical feasibility, environmental relevance, and originality), as described in Saidani et al. (2016) and inspired by the scoring system of Tyl et al. (2014) from the EcoASIT method (see Table 1 in sub-section 3.3).

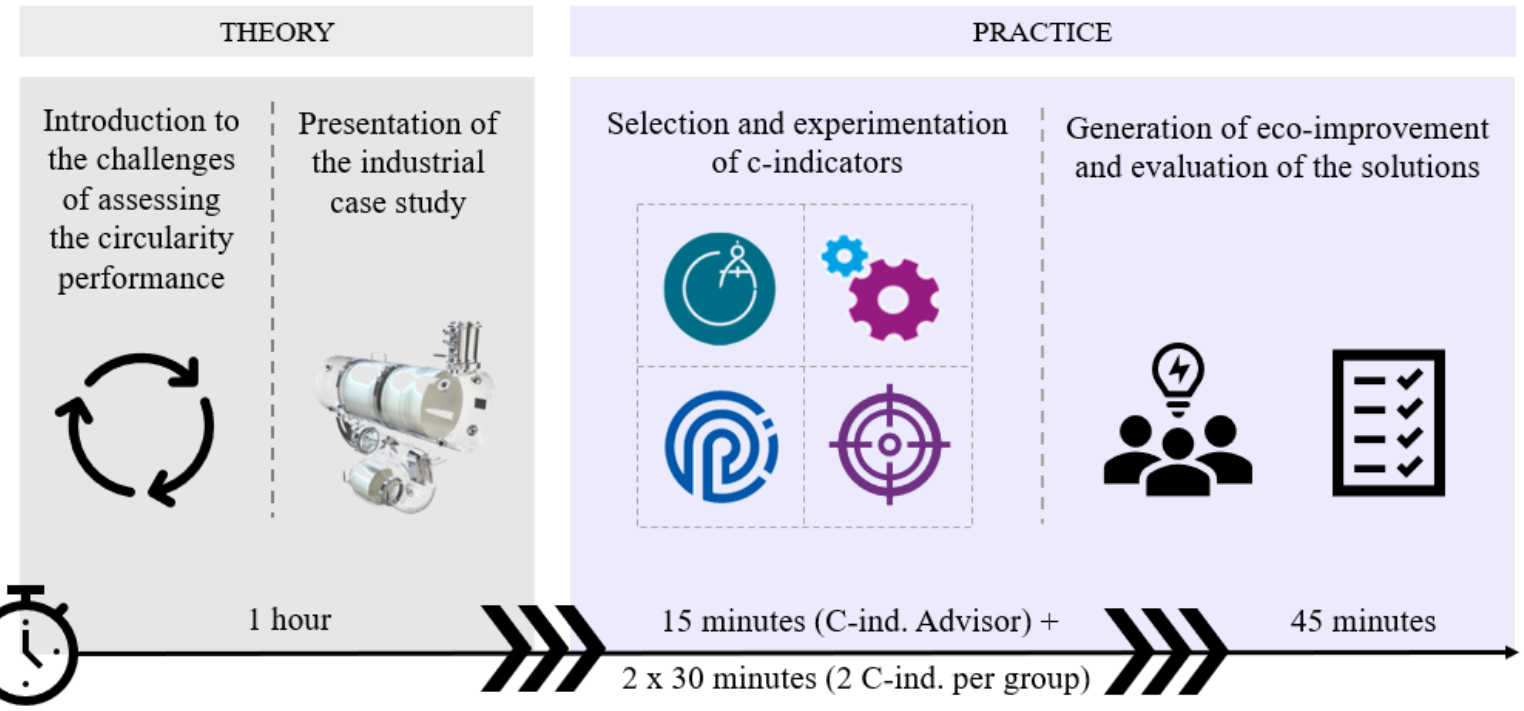

Figure 2. Organization and timeline of the workshop 


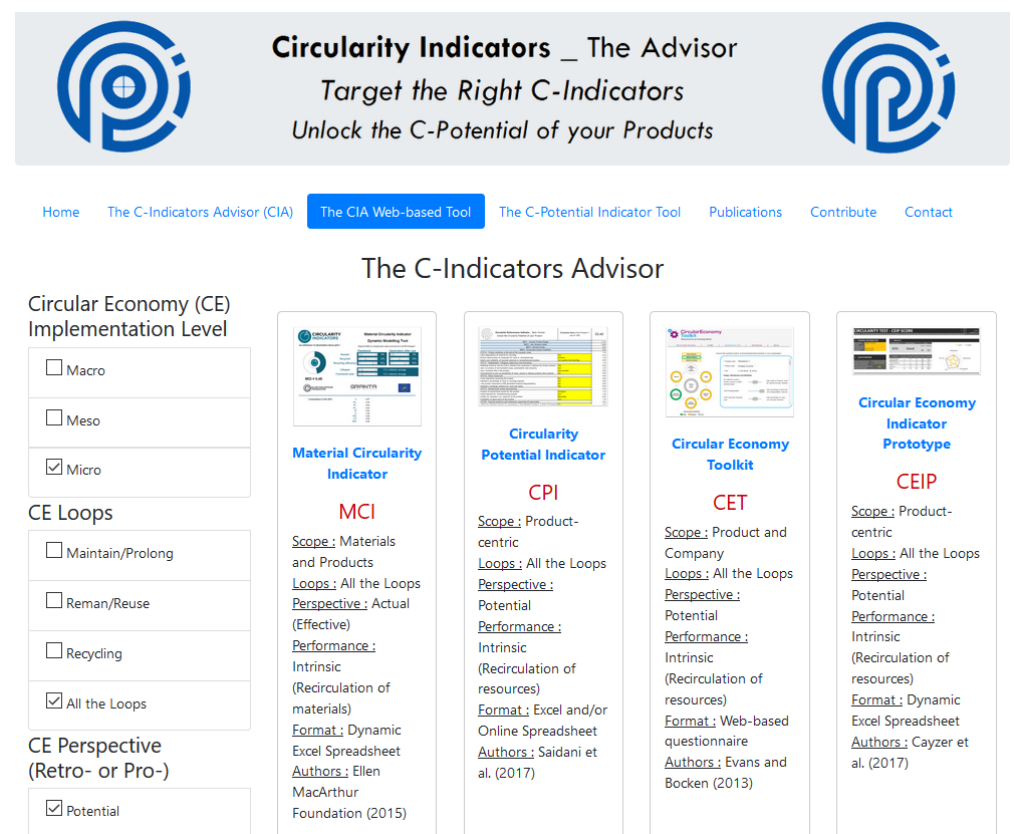

Figure 3. Web-based tool to select c-indicators (www.circulareconomyindicators.com)

\subsection{Main results and interpretations}

Regarding the variability and robustness of the circularity scores obtained by the different groups working on the same product, this new workshop conducted in 2019 confirmed the trends of the two previous workshop conducted in 2017 and 2018, as presented and discussed during the ICED19 conference (Saidani et al., 2019b). Here, we are focusing on analyzing how the outputs generated by these four c-indicators can be leveraged to guide products re-design in order to increase their circularity performance. In total, 34 improvement propositions have been generated with an average of 4.25 ideas, concepts or solutions per group per c-indicator. Table 1 below depicts the proposed solutions (two per c-indicator) to augment the circularity performance of the product, that have been assessed with the highest scores (the total being the arithmetic average of the scores given to the four criteria). The evaluation of the eco-improvements proposed by one group has been performed by another group after discussion within the score to agree on a score for each of the four criteria. In addition to their inner technical knowledge and culture to assess the eco-improvement, supporting information was provided to better understand the industrial context, and a facilitator, familiar with the product and its value chain, was here to answer their questions.

Table 1. Excerpt of the workshop's outcomes on designing for product circularity

\begin{tabular}{|c|c|c|c|c|c|c|}
\hline C-indicators & Proposed solutions to increase the circularity performance & EF & $\mathrm{TF}$ & ER & $\mathrm{O}$ & Total \\
\hline \multirow[t]{2}{*}{ MCI } & Increase recycled feedstock of cordierite and platinum & 3 & 3 & 3 & 1 & 2.5 \\
\hline & Look for substitute and alternative to platinum & 2 & 1 & 3 & 2 & 2 \\
\hline \multirow[t]{2}{*}{ CET } & $\begin{array}{l}\text { Partnership with third parties that provide maintenance and } \\
\text { recovery services to ensure sound end-of-life management }\end{array}$ & 2 & 3 & 3 & 1 & 2.25 \\
\hline & Make it easier to get access to the internal workings (parts) & 2 & 1 & 3 & 2 & 2 \\
\hline \multirow[t]{2}{*}{ CEIP } & Augment the warranty and/or develop a rental option & 2 & 3 & 3 & 2 & 2.5 \\
\hline & Use more recycled content for the cordierite substrate & 2 & 1 & 3 & 2 & 2 \\
\hline \multirow[t]{2}{*}{ CPI } & $\begin{array}{l}\text { Enable maintenance operations through better } \\
\text { maneuverability and disassembly of the catalytic converter }\end{array}$ & 3 & 3 & 3 & 1 & 2.5 \\
\hline & $\begin{array}{l}\text { Increase the awareness of stakeholders and users to the } \\
\text { environmental impact caused by the disposal of equipment }\end{array}$ & 2 & 2 & 3 & 2 & 2.25 \\
\hline
\end{tabular}

$\mathrm{EF}=$ Economic feasibility, $\mathrm{TF}=$ Technical feasibility $\mathrm{ER}=$ Environmental relevance, $\mathrm{O}=$ originality All the scores are assessed out of 3, see scoring system table in Saidani et al. (2016). 
As the MCI is mainly focused on material flows, it fosters and guides more directly towards the use of recycled and recyclable materials. For instance, increasing the recycled feedstock of cordierite (currently $0 \%)$ and platinum (33\%) during the manufacturing of new catalytic converters is an idea that has been generated by the two groups experimenting this c-indicator. While initially developed to measure the circularity potential of each design and related eco-system (including the value chain and business model(s) associated to the product), the initial assessment purpose of the CET, CPI and CEIP can practically be extended to find concepts and strategies aiming to close-the-loop on products. Looking at the assessment results of all the 34 ideas, concepts, or solutions generated, it appears the average score for the environmental relevance is relatively high ( 2.45 out of 3 ) which is a good empirical confirmation that improving the circularity performance of a product should lead to environmental benefits. On the other hand, the average score for the originality is low (1.3 out of 3) while the average scores for economic feasibility and technical feasibility are respectively of 1.9 and 2.15 out of 3. Furthermore, comparing the present outcomes with the previous results generated using the LiDS wheel during an ecoinnovation workshop on the same product (Saidani et al., 2016), one can argue that the proposed solutions were more original or advanced, even if in the pool of solutions with the highest scores, some propositions have close similarities, namely: develop partnership to create end-of-life value chain ( 2.5 out of 3); modular design; crankcase easily dismountable for recovery and to receive a new substrate; user awareness campaign; provide end-of-life guidance through a disassembly manual; marking spare parts to facilitate recycling; full cleaning after 15,000 hours of operation for second life ( 2 out of 3 ).

\section{Discussion: contributions of c-indicators in the design process}

By combining the literature survey on eco-design tools, the recent critical analyses of c-indicators, and the new insights provided by the workshops and experimentations of c-indicators aforementioned, first discussions are initiated to adequately position product-level c-indicators in the design process, and to foster the design of circular-friendly in new product development. In Figure 4, the four c-indicators tested are positioned against the conventional design processes and among the main clusters of ecodesign tools (as reviewed in Section 2). Hereafter, we further discuss the specific contributions of such tool-based c-indicators, and illustrate how they can be used in combination with particular eco-design tools to develop more circular and sustainable products.

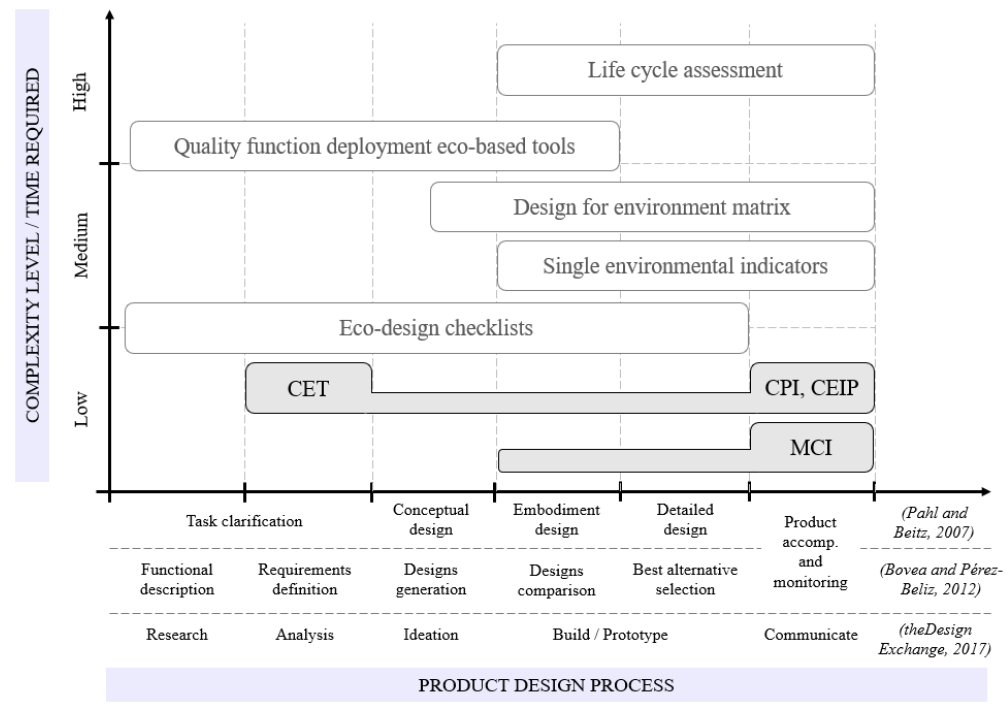

Figure 4. Mapping of four product-level c-indicators along the design process, and among the pool of main eco-design tools (inspired by Bovea and Pérez-Belis, 2012)

\subsection{Use of c-indicators as circular design tools}

The four c-indicators experimented are time-efficient (i.e., the assessment can be done in less than half an hour with sufficient data), and do not require a high level of expertise to be properly used. As such, 
they can be deployed not only to get a rapid and quite comprehensive overview of what is necessary to design circular-friendly products, but also to raise general awareness of designers or engineers on the key aspects to integrate in order to augment the circularity performance of products. Note that the MCI only requires a few inputs and is best used to quickly compare and select materials alternatives, as well as a communication or benchmarking tool. The list of questions to compute the CET, CPI, CEIP can be useful to define CE-oriented requirements, and the circularity scores can be used to rank and identify best designs, as well as to monitor product's circularity. They also both enable managers or designers to take informed decisions in a time-efficient way, and support communication on circularity through the value chain at operational and tactical levels (Kwok and Hallstedt, 2018). Yet, as their complexity level is relatively low, and because of their genericity (i.e., they can be applied to a wide range of industrial and technical products), industrial practitioners should not solely rely on them to build well-detailed designs. On this basis, it becomes interesting to consider a coupling with eco-design tools or design guidelines in a CE context, as recently reviewed by Bovea and Pérez-Belis (2018).

\subsection{Positioning and combination within eco-design tools}

Compared to single and more specific design for $\mathrm{X}$ approaches, such as design for cleaner production, design for remanufacturing, or design for recycling, the product-level c-indicators gather these different perspectives within the same framework in a practical and time-efficient manner. In this line, they can be deployed as a first screening tool in the space of alternative design possibilities when designing for a circular economy. Also, following the scores and potential promising areas of improvement indicated by the c-indicators (e.g., a low score attributed to the "ease of disassembly" criteria), they can orient industrial practitioners to complementary and more in-depth design methods and tools (e.g., design for disassembly guidelines) to fil this gap during the design process. Interestingly, these product c-indicators with their easy-to-use assessment framework could be used as eco-ideation tools, building on the current momentum around the $\mathrm{CE}$ transition. As such, they can contribute to fill a gap noticed by Vallet et al. (2016) on the fact even if a lot of eco-innovation tools are available, there are still barely adopted by industry due to their complexity, lack of adaptation, or simply lack of awareness on such tools.

\section{Conclusion and perspectives}

Circular product design is one of the fundamental aspect to advance the implementation of CE practices at an industrial level (Franco, 2019) and it is now acknowledged that c-indicators are key to assist and monitor the CE transition. On this basis, this research examines the relevance of c-indicators in a context of product design: four c-indicators are tested to explore how they can support the design of circular products; these product-centric c-indicators are then mapped against the design process and positioned within the pool of eco-design tools. Product-level c-indicators appear as convenient tools to be used during the design and development process, notably: to help the definition of CE-related requirements, to compare quantitatively the circularity potential of design alternatives, as well as to communicate and monitor managerial activities during the design process in a CE perspective. Particularity, they can rapidly guide practitioners towards areas of improvement and promising circular strategies. On this basis, there is an interesting potential to link these c-indicators accordingly with complementary and more specific design tools for developing superior circular and sustainable products. For future works, we encourage to further experiment c-indicators with industrial practitioners to figure out how they can concretely be adapted and/or integrated within their actual engineering design and development process. Last but not least, even if adopting CE strategies when developing products contribute a priori to enhance their sustainable performance, it remains of the utmost importance to evaluate systematically if an improvement of the circularity score leads to substantial sustainable benefits.

\section{References}

Blessing, L. and Chakrabarti, A. (2009), DRM, a Design Research Methodology, Springer-Verlag London Limited.

Blomsma, F. et al. (2019), "Developing a circular strategies framework for manufacturing companies to support circular economy-oriented innovation", Journal of Cleaner Production, In press. 
Bovea, M.D. and Pérez-Belis, V. (2012), "A taxonomy of ecodesign tools for integrating environmental requirements into the product design process", Journal of Cleaner Production, Vol. 20, pp. 61-71.

Bovea, M.D. and Pérez-Belis, V. (2018), "Identifying design guidelines to meet the circular economy principles: a case study on electric and electronic equipment", J. Environ. Manag, Vol. 228, pp. 483-494.

de Jesus, A. et al. (2018), "Eco-innovation in the transition to a circular economy: an analytical literature review", Journal of Cleaner Production, Vol. 172, pp. 2999-3018.

Franco, M.A. (2019), "A system dynamics approach to product design and business model strategies for the circular economy", Journal of Cleaner Production, In press.

Geissdoerfer, M. et al. (2017), "The Circular Economy-A new sustainability paradigm?", Journal of Cleaner Production, Vol. 143, pp. 757-768.

Gente, V. and Pattanaro, G. (2019), "The place of eco-innovation in the current sustainability debate", Waste Management, Vol. 88, pp. 96-101.

Hollander, M.C., Bakker, C.A. and Hultink, E.J. (2017), "Product Design in a Circular Economy: Development of a Typology of Key Concepts and Terms", Journal of Industrial Ecology, Vol. 21, pp. 517-525.

Janik, A. and Ryszko, A. (2019), "Circular economy in companies: an analysis of selected indicators from a managerial perspective", MAPE, Vol. 2 No. 1, pp. 523-535.

Jugend, D. et al. (2020), "Achieving environmental sustainability with ecodesign practices and tools for new product development”, In: Galanakis, C.M. (Ed.), Innovation Strategies in Environmental Science, Elsevier, pp. 179-207.

Kravchenko, M., Pigosso, D.C.A. and McAloone, T.C. (2019), "Towards the ex-ante sustainability screening of circular economy initiatives in manufacturing companies: Consolidation of leading sustainability-related performance indicators", Journal of Cleaner Production, In press.

Kwok, S.Y. and Hallstedt, S.I. (2018), "Sustainable Product Development: Challenges and Opportunities for Communicating Sustainability in a Value Chain”, NordDesign 2018, Linköping, Sweden, 14-17 August 2018.

McAloone, T.C. and Bey, N. (2009), Environmental improvement through product development: A guide, Danish Environmental Protection Agency, Copenhagen, p. 48.

Pahl, G. and Beitz, W. (2007), Engineering Design: A Systematic Approach, Springer-Verlag London.

Parchomenko, A. et al. (2019), "Measuring the circular economy - A Multiple Correspondence Analysis of 63 metrics", Journal of Cleaner Production, Vol. 210, pp. 200-216.

Pigosso, D. and McAloone, T.C. (2017), "How can design science contribute to a circular economy?", Proceedings of the 21st International Conference on Engineering Design (ICED 17), Vancouver, Canada, August 21-25, 2017, Vol. 5, Design for X, pp. 299-307.

Ramani, K. et al. (2010), “Integrated Sustainable Life Cycle Design: A Review”, Journal of Mechanical Design, Vol. 132, No. 8, pp. 1-15.

Rodrigues, V.P., Pigosso, D.C.A. and McAloone, T.C. (2016), "Process-related key performance indicators for measuring sustainability performance of ecodesign implementation into product development", Journal of Cleaner Production, Vol. 139, pp. 416-428.

Ruiz-Pastor, L. et al. (2019), "Analysis of the circularity metrics applicability in the conceptual product design stage”, 23rd International Congress on Project Management and Engineering, Málaga, Spain, July 10-12, 2019.

Saidani, M. et al. (2016), "Time-efficient eco-innovation workshop process in complex system industries", Proceedings of the 14th International Design Conference, Dubrovnik, Croatia, May 16-19, 2016.

Saidani, M. (2018), Monitoring and advancing the circular economy transition - Circularity indicators and tools applied to the heavy vehicle industry [PhD Thesis], Université Paris-Saclay.

Saidani, M. et al. (2019a), “A taxonomy of circular economy indicators”, Journal of Cleaner Production, Vol. 207, pp. 542-559.

Saidani, M. et al. (2019b), "Testing the robustness of circularity indicators: empirical insights from workshops on an industrial product", Proceedings of the 20th International Conference on Engineering Design (ICED 19), Delft, Netherlands, August 2019.

Smol, M., Kulczycka, J. and Avdiushchenko, A. (2017), "Circular economy indicators in relation to ecoinnovation in European regions", Clean Technol. Environ. Policy, Vol. 19, pp. 669-678.

Sustainn (2018), Zero-Waste Systems Engineering: A Process To Design Circular Products \& Services, Available at: http://www.wearesustainn.com/en/metodologias/.

TheDesignExchange (2017), Design methods. Available at: https://www.thedesignexchange.org/design_ methods.

Tyl, B. et al. (2014), “A comparative study of ideation mechanisms used in eco-innovation tools", Journal of Engineering Design, Vol. 25 No. 10-12, pp. 325-345.

Vallet, F. et al. (2016), "Research directions in eco-innovation: a French perspective", Int J Interact Des Manuf, Vol. 10, pp. 309-318. 